\title{
Yes-associated protein (YAP) induces a secretome phenotype and transcriptionally regulates plasminogen activator Inhibitor-1 (PAl-1) expression in hepatocarcinogenesis
}

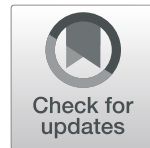

Simone Marquard ${ }^{1}$, Stefan Thomann ${ }^{1}$, Sofia M. E. Weiler ${ }^{1}$, Michaela Bissinger ${ }^{1}$, Teresa Lutz ${ }^{1,2}$, Carsten Sticht ${ }^{3}$, Marcell Tóth ${ }^{1}$, Carolina de la Torre ${ }^{3}$, Norbert Gretz ${ }^{3}$, Beate K. Straub ${ }^{4}$, Jens Marquardt ${ }^{5,6}$, Peter Schirmacher ${ }^{1}$ and Kai Breuhahn ${ }^{1 *}$ (1)

\begin{abstract}
Background: Overexpression and nuclear enrichment of the oncogene yes-associated protein (YAP) cause tumor initiation and support tumor progression in human hepatocellular carcinoma (HCC) via cell autonomous mechanisms. However, how YAP expression in tumor cells affects intercellular communication within the tumor microenvironment is not well understood.

Methods: To investigate how tumor cell-derived YAP is changing the paracrine communication network between tumor cells and non-neoplastic cells in hepatocarcinogenesis, the expression and secretion of cytokines, growth factors and chemokines were analyzed in transgenic mice with liver-specific and inducible expression of constitutively active YAP $\left(Y_{A P}{ }^{\text {127A }}\right.$ ). Transcriptomic and proteomic analyses were performed using primary isolated hepatocytes and blood plasma. In vitro, RNAinterference (RNAi), expression profiling, functional analyses and chromatin immunoprecipitation (ChIP) analyses of YAP and the transcription factor TEA domain transcription factor 4 (TEAD4) were performed using immortalized cell lines. Findings were confirmed in cohorts of HCC patients at the transcript and protein levels.

Results: YAP overexpression induced the expression and secretion of many paracrine-acting factors with potential impact on tumorous or non-neoplastic cells (e.g. plasminogen activator inhibitor-1 (PAI-1), C-X-C motif chemokine ligand 13 (CXCL13), CXCL16). Expression analyses of human HCC patients showed an overexpression of PAl-1 in human HCC tissues and a correlation with poor overall survival as well as early cancer recurrence. PAl-1 statistically correlated with genes typically induced by YAP, such as connective tissue growth factor (CTGF) and cysteine rich angiogenic inducer 61 (CYR61) or YAP-dependent gene signatures (CIN4/25). In vitro, YAP inhibition diminished the expression and secretion of PAl-1 in murine and human liver cancer cell lines. PAl-1 affected the expression of genes involved in cellular senescence and oncogene-induced senescence was confirmed in YAP ${ }^{\text {S127A }}$ transgenic mice. Silencing of TEAD4 as well as treatment with the YAP/TEAD interfering substance Verteporfin reduced PAI-1 expression. ChIP analyses confirmed the binding of YAP and TEAD4 to the gene promoter of PAI-1 (SERPINE1).

(Continued on next page)
\end{abstract}

\footnotetext{
* Correspondence: kai.breuhahn@med.uni-heidelberg.de

1 Institute of Pathology, University Hospital Heidelberg, Heidelberg, Germany

Full list of author information is available at the end of the article
}

\section{$\triangle B M C$}

(c) The Author(s). 2020 Open Access This article is licensed under a Creative Commons Attribution 4.0 International License, which permits use, sharing, adaptation, distribution and reproduction in any medium or format, as long as you give appropriate credit to the original author(s) and the source, provide a link to the Creative Commons licence, and indicate if changes were made. The images or other third party material in this article are included in the article's Creative Commons licence, unless indicated otherwise in a credit line to the material. If material is not included in the article's Creative Commons licence and your intended use is not permitted by statutory regulation or exceeds the permitted use, you will need to obtain permission directly from the copyright holder. To view a copy of this licence, visit http://creativecommons.org/licenses/by/4.0/ The Creative Commons Public Domain Dedication waiver (http://creativecommons.org/publicdomain/zero/1.0/) applies to the data made available in this article, unless otherwise stated in a credit line to the data. 


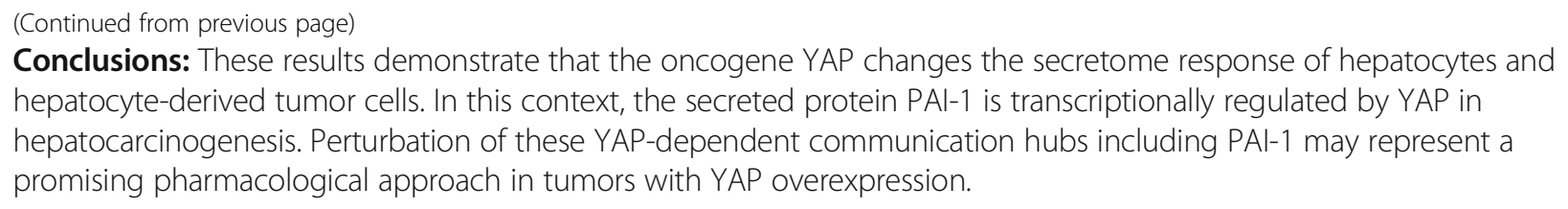

\section{Plain English summary}

Tumor cells communicate with other tumor cells and nonneoplastic cells to create a growth-supportive environment. Indeed, a comprehensive understanding of these communication networks allows to investigate novel therapeutic strategies that 'disturb' abnormal crosstalk between these cells. The goal is to normalize the tumor environment and to counteract tumor growth. In this study, we focus on the oncogene YAP (yes-associated protein) that causes liver tumor formation. Using independent and complementary screening techniques and model systems, we identified several secreted factors that are induced by YAP in liver cells (secretome phenotype) and that could adjust cell-cell communication in a tumor-supporting manner. For example, high YAP-dependent plasminogen activator inhibitor-1 (PAI1) levels in liver cancer patients associate with poor clinical outcome. PAI-1 regulates the expression of factors associated with cellular senescence. Mechanistically, we show that YAP together with a transcription factor of the TEA domain transcription factor family TEAD4 controls PAI-1 expression and secretion. We conclude that oncogenes such as YAP control the expression of secreted factors to generate a tumorsupportive microenvironment. This paracrine communication could serve as adjusting screw for the normalization of cell communication.

\section{Background}

The Hippo signaling pathway and its negatively regulated downstream effector yes-associated protein (YAP) control tissue growth and organ size in embryogenesis as well as under regenerative conditions [1]. As described for the liver in great detail, dysregulation of the pathway is associated with nuclear YAP enrichment, which is leading to uncontrolled hepatocellular proliferation and malignant transformation [2]. YAP overexpression in about $30 \%$ of all cases defines liver cancer patients (hepatocellular carcinoma; HCC) with shorter survival and early cancer recurrence, illustrating the necessity to understand how this protein supports tumorigenesis [3].

So far, different YAP-driven mechanisms that contribute to tumor cell initiation and progression have been described. For the liver, they include the expansion of cells with a progenitor phenotype, which are the origin for the development of liver tumors with mixed differentiation [4-6]. YAP also supports migration/invasion in a tumor cell autonomous manner [7]. Lastly, YAP-mediated hepatocellular proliferation leads to chromosome instability (CIN) and accumulation of genetic alterations, which represent the basis for tumor initiation $[3,8]$. Next to these tumor cell-autonomous mechanisms, heterologous cell communication via secreted proteins could contribute to carcinogenesis. Indeed, recent data illustrate that YAP overexpression in tumor cells controls the expression and secretion of growth factors and cytokines already in early stages of hepatocarcinogenesis, creating a tumor-supporting microenvironment [9]. Interestingly, YAPdependent paracrine-acting proteins produced by hepatocytes and tumor cells may affect non-parenchymal liver cells (e.g. endothelial cells, hepatic stellate cells, and Kupffer cells) or they may control the behavior of hepatocellular cells in an autocrine manner. However, if the Hippo/YAP signaling axis directly controls these paracrine-acting factors via transcriptional regulation or if expression of these proteins is the consequence of secondary effects is not well understood. In addition, the relevant downstream effectors that mediate biologically relevant processes of YAP in carcinogenesis are not well-defined. Lastly, identification of YAP-dependent communication hubs could lead to the development of specific therapies. Targeting these potential 'points of interference' would be of special interest for patients with YAP overexpression.

To understand how YAP expression in HCC cells could affect the production of secreted factors, different technical approaches were used. By using transcriptome and proteome analyses, we describe the secretome of primary murine hepatocytes that overexpress active YAP. As exemplified for plasminogen activator inhibitor1 (PAI-1), we show that overexpression of this factor in human hepatocellular carcinoma (HCC) patients correlates with poor clinical outcome and expression of known YAP target genes. In addition, PAI-1 controls the expression of genes involved in cellular senescence. Together with TEA domain transcription factor 4 (TEAD4), YAP transcriptionally regulates PAI-1 expression in human and murine liver cancer cell lines.

\section{Materials and methods}

Sequences for siRNAs and primers (mouse and human) as well as antibodies (incl. dilutions and applications) are listed in Supplementary Tables S1, S2, S3, S4. 


\section{Mouse work}

LAP-tTA/Col1A1-YAP ${ }^{\text {S127A }}$ (LAP-YAP) mice were used in this study $[6,10]$. For transgene repression of constitutively active $\mathrm{YAP}^{\mathrm{S} 127 \mathrm{~A}}$, mice received $2 \mathrm{mg} / \mathrm{ml}$ doxycycline in their drinking water supplemented with 10 $\mathrm{mg} / \mathrm{ml}$ sucrose. For transgene induction, doxycycline was withdrawn at the age of 10 weeks. Control mice (with doxycycline) and animals with $\mathrm{YAP}^{\mathrm{S} 127 \mathrm{~A}}$ expression were sacrificed at time points that are indicated below.

\section{Isolation of primary hepatocytes and extraction of plasma samples}

Primary murine hepatocytes were isolated from LAPtTA/Col1A1-YAP ${ }^{\text {S127A }}$ (LAP-YAP) mice 12 weeks after doxycycline withdrawal. Cells were cultivated on collagen I-coated $10 \mathrm{~cm}$ dishes (Corning Life Sciences, Amsterdam, Netherlands) in Williams adhesion medium (Biochrom, Berlin, Germany) containing $100 \mathrm{nM}$ dexamethasone, $2 \mathrm{mM}$ glutamin, 10\% FCS and 1\% penicillin/ streptomycin (Sigma-Aldrich, Taufkirchen, Germany) for $4 \mathrm{~h}$ at $37^{\circ} \mathrm{C}$ to allow attachment. After removing non-adherent cells, attached hepatocytes were cultured for $24 \mathrm{~h}$ and subjected to protein and RNA isolation. No obvious changes between wildtype and YAP ${ }^{\mathrm{S} 127 \mathrm{~A}}$ transgenic hepatocytes with regard to cell adhesion were observed.

For the collection of murine blood plasma (13 weeks after $\mathrm{YAP}^{\mathrm{S} 127 \mathrm{~A}}$ induction), mice were euthanized by an intraperitoneal injection using Ketamin/Xylazine and whole blood was obtained through an intracardial puncture using a heparin-coated $1 \mathrm{ml}$ syringe (BD, Heidelberg, Germany). To obtain blood plasma, samples were centrifuged (30 min, $2000 \times g$ at room temperature). Plasma samples were stored at $-80^{\circ} \mathrm{C}$.

\section{Cell culture, RNA-interference, and Verteporfin treatment} The murine HCC cell line Hepa1-6 (CLS, Eppelheim, Germany) as well as the human cell lines Sk-Hep1 (ATCC; LGC Standards, Wesel, Germany), SNU-182 (ATCC; LGC Standards), HEK-293 cells were cultured in DMEM and RPMI, (Sigma-Aldrich) supplemented with 10\% FCS (Gibco/Life Technologies) and 1\% penicillin/streptomycin (Sigma-Aldrich) at $37^{\circ} \mathrm{C}$ and $5 \% \mathrm{CO}_{2}$, respectively. Cells were seeded in 6 -well plates 1 day prior to transfection with gene-specific small interfering RNAs (siRNAs). siRNAs were received from Eurofins MWG Operon (Ebersberg, Germany) and diluted in OptiMEM (Gibco/Life Technologies) to a final concentration of 20 or $40 \mathrm{nM}$. Oligofectamine (Life Technologies) was used as transfection reagent according to the manufacturer's protocol. After incubation at room temperature for $15 \mathrm{~min}$, the reagents were mixed, incubated for another $10 \mathrm{~min}$ at room temperature and distributed onto the cells covered with OptiMEM. One millilitre DMEM was added after $4 \mathrm{~h}$. The medium was replaced by FCS-free medium after $24 \mathrm{~h}$. Cells and supernatant were harvested $48 \mathrm{~h}$ after transfection. Untreated cells and scrambled siRNA-transfected cells (scr.) were used as controls as indicated.

The YAP/TEAD-Inhibitor Verteporfin (Sigma-Aldrich) was dissolved in DMSO to prepare a stock solution of 2 $\mathrm{mM}$ according to the manufacturer's instructions. One day after seeding, cells were treated with Verteporfin $(0.25$ to $1 \mu \mathrm{M})$. Medium was changed after $24 \mathrm{~h}$ and cells/supernatant were harvested after $48 \mathrm{~h}$. DMSOtreated cells served as control (max. volume fraction of 0.05\% DMSO in cell culture medium).

\section{Preparation of total RNA, reverse transcription and real- time PCR}

For isolation of total RNA from cultured cells, the NucleoSpin RNA II kit (Machery-Nagel, Düren, Germany) was applied. For RNA extraction from tissue samples, the Precellys Ceramic Kit 1.4 and the Precellys 24 Homogeniser were used (Peqlab, Erlangen, Germany), followed by RNA purification using the NucleoSpin RNA II kit.

For cDNA-synthesis, $1 \mu \mathrm{g}$ of total RNA was reverse transcribed using the Revert Aid H Minus RT kit (Thermo Fisher Scientific, Darmstadt, Germany). Semiquantitative real-time PCR was performed with ABsolute qPCR SYBR Green ROX Mix (Steinbrenner, Wiesenbach, Germany) using the following cycling program: $95^{\circ} \mathrm{C}$ for $15 \mathrm{~min}$ followed by 40 cycles of $95^{\circ} \mathrm{C}$ for $15 \mathrm{~s}$ and $60^{\circ} \mathrm{C}$ for $1 \mathrm{~min}$. Melting curve analysis was applied for the validation of product specificity. For human cells, $\beta 2$-microglobulin (B2M) and ribosomal protein L41 (RPL41) were used for normalization. For experiments with murine cells, $\beta$-actin (ACTB) was used as housekeeping gene.

For tissue analyses, stable genes for normalization were identified by the GeNorm software [11]. The panel of reference genes for human tissue samples included B2M, peptidylprolyl isomerase A (PPIA), RPL41, TATAbox binding protein (TBP) and serine and arginine rich slicing factor 4 (SRSF4). For mouse samples, ACTB, glyceralaldehyd-3-phosphate dehydrogenase (GAPDH), hypoxanthine-phosphoribosyltransferase (HPRT) and PPIA were measured.

\section{Protein isolation, acetone precipitation and Western immunoblotting}

For isolation of total protein from cultured cells, 10x Cell Lysis Buffer (Cell Signaling/New England Biolabs, Frankfurt, Germany) supplemented with PhosStop (Roche, Mannheim, Germany) and Protease-Inhibitor Mix G (SERVA, Heidelberg, Germany) were used. Protein isolation from tissue samples (13 weeks after $\mathrm{YAP}^{\mathrm{S} 127 \mathrm{~A}}$ induction) was performed using the Precellys 
Ceramic Kit 1.4 and the Precellys 24 Homogeniser (Peqlab). Supernatant containing protein lysates was collected after sonication and centrifugation.

For detection of secreted proteins in cell culture supernatant, acetone precipitation was performed. After cell debris was removed by centrifugation, $1.5 \mathrm{ml}$ of the samples were mixed with $6 \mathrm{ml}$ ice-cold acetone and incubated at $-20^{\circ} \mathrm{C}$ for $1 \mathrm{~h}$. Samples were centrifuged at $3800 \mathrm{x} g$ at $4{ }^{\circ} \mathrm{C}$ for $30 \mathrm{~min}$ to form a protein pellet. After discarding the supernatant, the pellet was dried for 30 min at room temperature and resuspended in $300 \mu \mathrm{l}$ lysis buffer.

Protein amounts were measured with the NanoDrop ND-1000 spectrophotometer (Thermo Fisher Scientific; wavelength: $280 \mathrm{~nm}$ ). After dilution in loading buffer (2\% SDS, $10 \%$ glycerol, $5 \% \beta$-mercaptoethanole, $0.002 \%$ bromphenol blue, $62.5 \mathrm{mM}$ Tris- $\mathrm{HCl}$ ), equal amounts of total protein per lane were separated by $8-12 \%$ sodium dodecyl sulfate (SDS) polyacrylamide gel electrophoresis and blotted on a nitrocellulose membrane (GE Healthcare, Solingen, Germany). The membranes were blocked with $5 \%$ milk or bovine serum albumin (BSA) in TBS-T (Tris-buffered saline/Tween 20). All primary antibodies were added and incubated at $4{ }^{\circ} \mathrm{C}$ overnight. All secondary antibodies were also diluted in a 5\% milk and BSA/ TBS-T solution, respectively (1:20,000; IRDye 680 and 800, LI-COR Biosciences, Bad Homburg, Germany) and incubated at room temperature for $1 \mathrm{~h}$. Images were acquired with the Odyssey Sa Infrared Imaging System (LI-COR Biosciences). For normalization, the appropriate housekeeping gene was detected (ACTB and GAPD $\mathrm{H}$ for cell culture samples, $\beta$-tubulin for tissue samples, and albumin for plasma samples).

\section{Chromatin-Immunoprecipitation (ChIP)}

Using the JASPAR database, the promoter of human and mouse SERPINE1 gene (coding for PAI-1) was searched for potential binding sites of TEAD4 [12]. Negative control primers were designed based on random sequences downstream of the potential TEAD4 binding sites. The ChIP-analysis was performed as previously described [3]. Promoter binding was compared to an input sample, which was removed and frozen at $-20{ }^{\circ} \mathrm{C}$ prior to sample preclearing. Crosslink reversion and purification of DNA of the input sample were performed as for the ChIP samples.

\section{Luciferase assay}

Assay was performed as previously described [3]. In brief, a 250 fragment of the human SERPINE1 promoter was cloned in the pGL3 basic firefly luciferase vector (pGL3-PAI-1) using MluI/XhoI restriction enzymes. pGL3-PAI-1 was transiently transfected with the pRLCMV-Renilla vector (ratio: 1:1 or 1:4). For inhibition experiments, cells were first transfected with the respective siRNAs for $24 \mathrm{~h}$, followed by transfection with the pGL3/pRL vectors. The mutation in the TEAD4 binding site was included using the following primer for: $5^{\prime}$ CAG CAG CTG AAC TCC TGC AGC TCA G-3' and rev: 5'-CTG AGC TGC AGG AGT TCA GCT GCT G3'. Underlined: TEAD4 binding site; bold: mutated base. Amplification of fragments was done using the Phusion polymerase (Thermo Fisher Scientific). For YAP overexpression, human YAP was cloned into a pDEST vector.

\section{Expression profiling}

For the analysis of PAI-1 dependent gene expression, PAI1 was transiently silenced in human Sk-Hep1 cells using siRNA. Cells were harvested 2 days after transfection and total RNA was isolated. RNAi efficiency was validated by real-time PCR and western immunoblotting.

For expression profiling of primary isolated hepatocytes and immortalized cells after PAI-1 inhibition, only samples with a RNA integrity number (RIN) $>7$ were used. Purified and fragmented complementary DNA was generated according to the manufacturer's instructions (Thermo Fisher Scientific, Waltham, MA, USA). Fragments were biotin-labelled prior to hybridization on MoGene-2_0-st chips using a GeneChip Hybridisation oven 640. Successive staining and scanning were performed with a GeneChipFluidics Station 450 and a GeneChip Scanner 3000, respectively (Thermo Fisher Scientific).

After gene annotation, the fluorescence intensity was measured, normalized, and differential expression was statistically assessed using the software package SAS JMP7 genomics (SAS Institute, Cary, NC, USA). As cutoff, a false discovery rate (FDR) value of 0.05 was considered as significant. To assure a homogeneous distribution of the generated data, principal component analysis (PCA) was performed to compare the similarity of individual biological samples in this study. To identify pathways and cellular processes with significant enrichment of differentially expressed genes, gene set enrichment analysis (GSEA) was performed. Identified KEGG pathways, including "Cytokine - Cytokine Receptor Interaction - mmu04060", were used for heatmap generation. For the transcriptomic response after transient inhibition of PAI-1, the KEGG pathway "cellular senescence hsa04218" and its normalized enrichment score were used.

\section{Antibody array}

For proteome analysis of murine blood plasma samples, the Mouse XL Cytokine Array Kit by R\&D Systems (Minneapolis, USA) was applied according to the manufacturer's protocol. Plasma samples of wildtype $(n=3)$ and $\mathrm{YAP}^{\mathrm{S} 127 \mathrm{~A}}$ mice $(n=5)$ were analyzed. After 
incubating with biotinylated detection antibodies for $1 \mathrm{~h}$ at room temperature, diluted IRDye $800 \mathrm{CW}$ streptavidin was administered and the arrays were scanned using Odyssey Sa Infrared Imaging System (LI-COR Biosciences). Background signal was subtracted, and average intensity of the reference spots was used for normalization.

\section{Immunohistochemistry}

For immunohistochemical staining, formalin-fixed and paraffin embedded tissue sections were first deparaffinized and rehydrated by washing with xylene (3x for 6 min each time), $100 \%$ ethanol, $96 \%$ ethanol, $70 \%$ ethanol (each $2 \mathrm{x}$ for $5 \mathrm{~min}$ each time) and finally rinsed in distilled $\mathrm{H}_{2} \mathrm{O}$. Antigen retrieval was performed in a pressure cooker for $15 \mathrm{~min}$ by covering the slides with Target Retrieval Solution (citrate buffer, pH 6.0; DAKO, Hamburg, Germany). After cooling down the slides for $30 \mathrm{~min}$ and washing with TBS ( $2 x$ for 5 min each time), the primary antibody was applied for $1 \mathrm{~h}$. Slides were washed again with TBS twice for 5 min prior to incubation with the biotinylated secondary antibody for $25 \mathrm{~min}$ at room temperature, followed by $2 \times 5 \mathrm{~min}$ each time TBS washes, 10 min $\mathrm{H}_{2} \mathrm{O}_{2}$ block, $2 \times 5$ min each time TBS washes and Streptavidin-HRP (DAKO) incubation for $25 \mathrm{~min}$. After $2 \times 5 \mathrm{~min}$ each time TBS washes, peroxidase was detected by AEC (3-amino-9-ethylcarbazole, DAKO) followed by a haematoxylin stain.

\section{$\beta$-Galactosidase staining}

For the detection of senescent cells, $\beta$-galactosidase stain was performed using frozen sections of murine liver tissue from wildtype $(n=8)$ and $\mathrm{YAP}^{\mathrm{S} 127 \mathrm{~A}}$ mice $(n=8)$. After fixation in $0.5 \%$ glutaraldehyde/PBS for $15 \mathrm{~min}$, slides were washed once with PBS and twice with PBS (pH 5.5) supplemented with $1 \mathrm{mM} \mathrm{MgCl} 2$ (each for $5 \mathrm{~min}$ ). Freshly prepared X-Gal staining solution $(92.5 \% \mathrm{PBS} / \mathrm{MgCl} 2,5 \%$ 20x KC-Buffer, 2.5\% 40x X-Gal (Roche)) was applied and incubated overnight at $37^{\circ} \mathrm{C}$ in a wet chamber, followed by $3 \times 5 \mathrm{~min}$ PBS washes and counterstaining with eosin. For quantification of $\beta$-galactosidase positive cells, the FIJI (https://fiji.sc/) segmentation tool "Trainable WEKA Segmentation" was used.

\section{Human samples}

Transcriptomic and survival data of a human HCC cohort from 242 patients were reanalyzed [13]. Independent RNA samples from $20 \mathrm{HCC}$ patients were surgically resected at the University Hospital of Mainz.

\section{Tissue microarray}

The tissue microarray (TMA) contained 7 nontumorous liver tissues and $91 \mathrm{HCC}$ tissues (grading: 7x G1, 66x G2, 14x G3, 4x G4). The evaluation of the tissue samples was performed by a scoring system depending on the percentage of positive tumor cells $(0=$ no expression, $1=$ less than $1 \%$ positive, $2=1-9 \%$ positive, $3=10-50 \%$ and $4=$ more than $50 \%$ positive cells) and staining intensity $(0=$ negative, $1=$ low, $2=$ medium, 3 =strong) of the immunohistochemical staining. The product of both values resulted in a score ranging from 0 to 12 . A score equal to or higher than 6 was defined as overexpression of the investigated protein. The analysis was performed by two experienced investigators (S.M., M.T.).

\section{Data analysis and statistics}

Western immunoblotting, ChIP analysis and qPCR experiments were biologically repeated 2 or 3 times. For statistical analysis and graph preparation the software Excel and SPSS were used. Data are shown as mean \pm standard deviation. For statistical comparison of two independent groups, the Mann-Whitney U test was applied. Survival and recurrence data of cancer patients were analyzed using the with log-rank test. Spearman's rho was used to determine statistical dependence of ordinal scaled data. Significance levels were defined as $p^{*} \leq 0.05$, $p^{* *} \leq 0.01$ and $p^{* * *} \leq 0.001$. Heatmaps were created using the online tool Morpheus (https://software. broadinstitute.org/morpheus/).

\section{Results}

\section{YAP regulates the hepatocellular secretome in an HCC} tumor model

In order to obtain a comprehensive overview of how YAP may affect the tumor microenvironment in a paracrine manner, a mouse model with inducible expression of human YAP lacking the phosphorylation site at amino acid $127\left(\mathrm{YAP}^{\mathrm{S} 127 \mathrm{~A}}\right)$ was used $[3,10]$. For this, mice carrying a doxycycline-dependent allele for $\mathrm{YAP}^{\mathrm{S} 127 \mathrm{~A}}$ were crossed with mice expressing the tetracycline transactivator (tTA) under control of the liver activator protein (LAP) promoter (Tet-off system). Withdrawal of doxycycline in these mice induced a robust overexpression of constitutively active $\mathrm{YAP}^{\mathrm{S} 127 \mathrm{~A}}$ compared to control animals. This $\mathrm{YAP}^{\mathrm{S} 127 \mathrm{~A}}$ expression caused severe hepatomegaly after 8-12 weeks and tumor formation after 1215 weeks of transgene induction $[3,6]$.

In a first step, cytokine abundance in blood plasma samples derived from wildtype (WT) and $\mathrm{YAP}^{\mathrm{S127A}}$ transgenic mice was analyzed using a proteome profiler array ( $n=111$ cytokines). The quantitative analysis revealed that 10 proteins were significantly induced at least 2 -fold in blood samples from YAP ${ }^{\mathrm{S127A}}$ mice (Fig. 1a). These factors included $C-X-C$ motif chemokine ligand 13 (CXCL13), CXCL16 and plasminogen activator inhibitor-1 (PAI-1; synonym: serine protease inhibitor E1 (SERPINE1)). 
However, this screen was not informative regarding the cellular source of the secreted proteins. For this reason, we decided to further examine primary hepatocytes isolated from WT and $\mathrm{YAP}^{\mathrm{S} 127 \mathrm{~A}}$ expressing mice using transcriptome analysis ( $n=3$ from each group). Expression profiling revealed that the expression of 2212 genes differed significantly between WT and YAP ${ }^{\mathrm{S} 127 \mathrm{~A}}$ hepatocytes. Interestingly, many of these differentially expressed genes were secreted factors or were involved in signal transduction as exemplified for cytokine-cytokine receptor interaction (KEGG pathway mmu04060), (Fig. 1b). For this pathway, 93 genes were differentially expressed $($ FDR $\leq 0.05)$, with many secreted factors and receptors induced in $\mathrm{YAP}^{\mathrm{S} 127 \mathrm{~A}}$ hepatocytes indicating that YAP induced a secretory response (Fig. 1b, supplementary Table S5). In total, 47 of the significantly regulated factors were receptors, while 46 genes represented secreted ligands. For further comparative analyses, we focused on ligands that were positively regulated in $\mathrm{YAP}^{\mathrm{S} 127 \mathrm{~A}}$-transgenic hepatocytes (38/47).

For confirmation, $\mathrm{YAP}^{\mathrm{S} 127 \mathrm{~A}}$-dependent expression of known target genes such as connective tissue growth factor (CTGF) and cysteine rich angiogenic inducer 61
(CYR61) were analyzed by real-time PCR using samples derived from primary isolated murine hepatocytes (Fig. 1c). In addition, overexpression of several identified paracrine-acting factors in $\mathrm{YAP}^{\mathrm{S} 127 \mathrm{~A}}$-positive cells was demonstrated including CXCL13, CXCL16, platelet derived growth factor subunit B (PDGFB) and PDGFC (Fig. 1c). Lastly, factors that were identified in blood plasma samples at protein level and in primary hepatocytes at transcript level were analyzed in tissue lysates derived from WT and $\mathrm{YAP}^{\mathrm{S} 127 \mathrm{~A}}$ transgenic mice (Fig. 1d). Elevated expression of these candidates was also confirmed in tissue lysates derived from $\mathrm{YAP}^{\mathrm{S127A}}$ expressing mice (e.g. PAI-1, CXCL16).

In the last step, a comparative analysis of protein (plasma) and transcript data (primary hepatocytes as well as liver tissues) was performed. In total, 5 potential YAP target genes were regulated in at least two of the performed approaches (Fig. 2).

Together, these data illustrate that in vivo YAP controls the expression of several secreted factors, which may individually contribute to the modulation of the microenvironment and tumor cells in a paracrine manner.

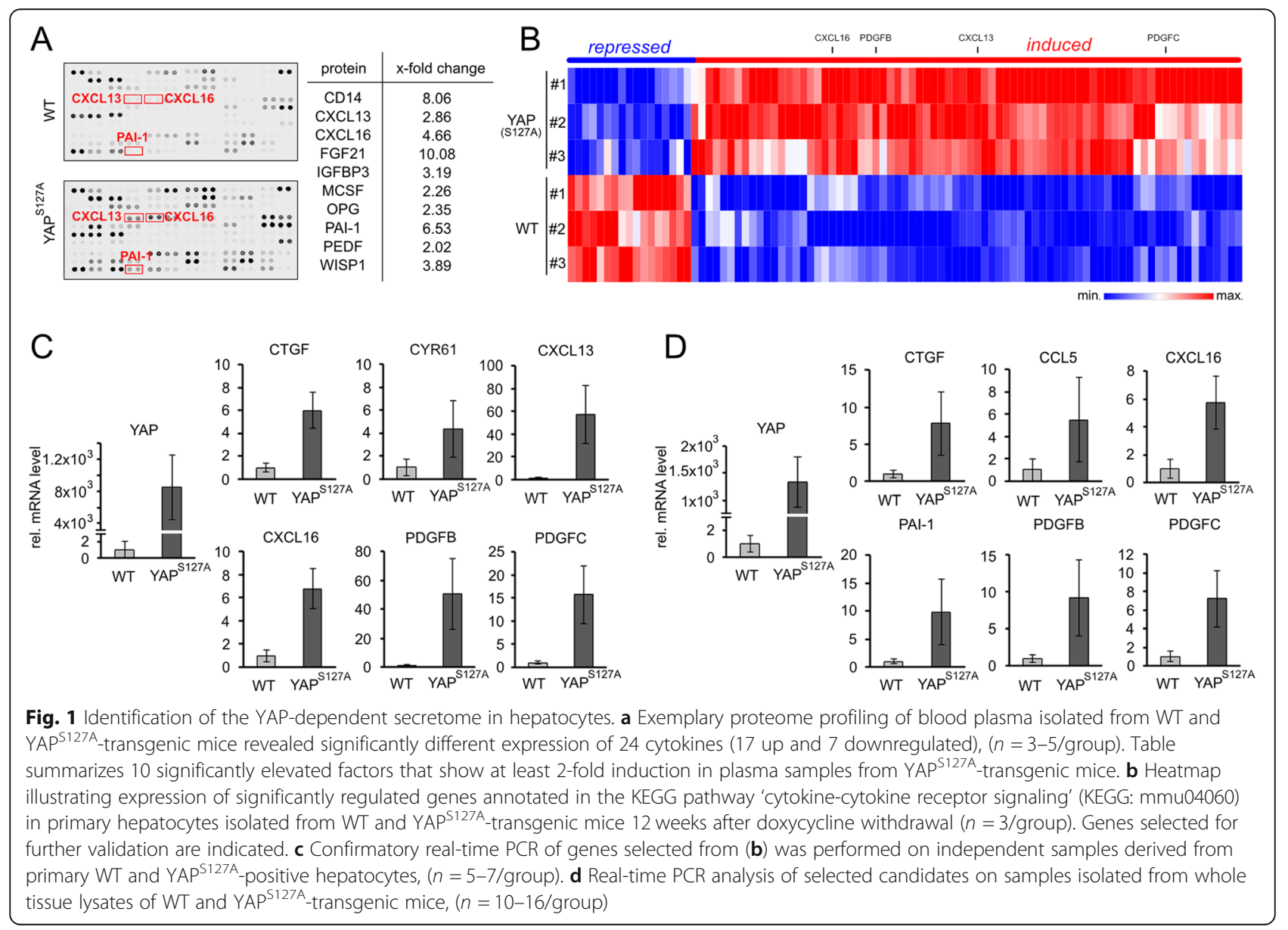




\section{Overexpression of YAP-regulated PAI-1 correlates with unfavorable HCC prognosis}

We then decided to investigate if the secreted factors CXCL13, PAI-1, PDGFB and PDGFC also correlated with HCC patient prognosis and analyzed a cohort consisting of $242 \mathrm{HCC}$ cases [13], (data for CXCL16 was not available). For this, we correlated the abundance of the remaining 4 candidates with survival and tumor recurrence. Interestingly, only for PAI-1 a robust and significant association between high-level expression and poor clinical outcome was detectable (Fig. 3a/b). For this reason, all further analyses focused on the role of PAI-1 in hepatocarcinogenesis.

First, PAI-1 overexpression was substantiated in an independent HCC cohort consisting of 19 HCC tissues and corresponding non-tumorous liver tissues. Indeed, real-time PCR analysis revealed an at least 2-fold induction of PAI-1 in about $26 \%$ of all examined HCC tissues compared to the control samples (Fig. 3c, upper panel). Elevated PAI-1 and YAP protein levels (IHC score $\geq 6$ ) could be detected in 25 and $24 \%$ of HCC patients by analyzing PAI-1 and YAP stainings (Fig. 3c, lower panel). However, a significant correlation between nuclear YAP positivity and PAI-1 was not detectable in this cohort.

YAP transcript levels were in most cases not or only moderately altered in HCC cells, since its aberrant activation is caused by nuclear translocation. For this reason, we tested if PAI-1 expression was associated with the expression of typical YAP target genes and YAP-induced gene signatures, which can be considered as an approximation for YAP activity [3]. Indeed, a moderate but significant association between PAI-1, CTGF and CYR61, as well as the YAPdependent CIN signatures (CIN25 and CIN4) was observed in samples derived from HCC patients (Fig. 3d). This statistical analysis illustrated that transcriptional YAP activity in $\mathrm{HCC}$ tissue correlated with increased PAI-1 expression.

In sum, the overexpression of the potential YAP target gene PAI-1 was associated with worse clinical outcome of HCC patients and its expression correlated with typical YAP downstream targets genes.

\section{YAP regulates PAI-1 expression and secretion}

In our initial screening approaches, differences at transcript (in tissue samples) or protein levels (in blood samples) could be caused by cells that were negative for YAP (e.g. non-parenchymal cells). For this reason, our findings of YAP-dependent PAI-1 expression were confirmed using immortalized cancer cell lines of hepatocellular origin.

First, silencing of YAP by RNAinterference (RNAi) was performed in the murine HCC cell line Hepa1-6 using two independent siRNAs. In comparison to untreated and scrambled siRNA-transfected cells, the efficient knockdown of YAP led to reduced transcript levels of several identified factors including CTGF, CYR61, CXCL16, PDGFB/C and PAI-1 (Fig. 4a). Second, we specifically tested the impact of YAP silencing on PAI-1 expression in a human cancer cell line. As expected from the previous results, YAP silencing reduced PAI-1 transcript abundance (Fig. 4b, left panel). More important, the amount of PAI-1 in total protein extracts and cell culture supernatant was diminished by 50 and $90 \%$, respectively, further supporting the idea that PAI-1 might mediate YAP-induced cell extrinsic effects (Fig. 4b, right panel). Lastly, significantly elevated PAI-1 protein levels were detectable in total protein extracts of liver tissues as well as plasma samples derived from mice with inducible YAP ${ }^{\text {S127A }}$ expression (Fig. 4c).

Together, these results from murine and human model systems show the YAP-dependent regulation of PAI-1 expression.

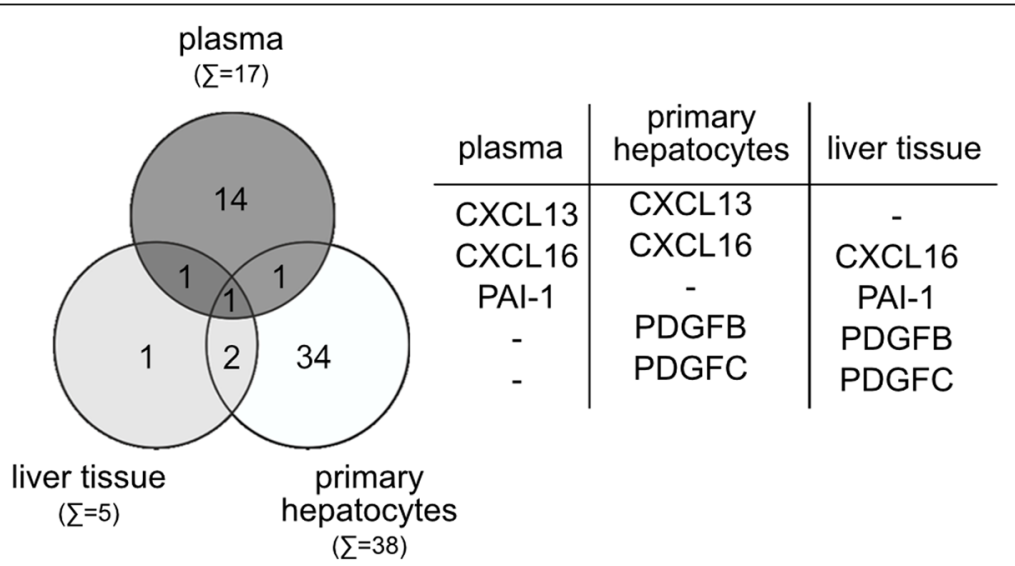

Fig. 2 Identification of PAI-1 as potential YAP target gene in HCC cells. Intersection analysis comparing the different technical approaches revealed that 5 secreted candidates were identified by at least 2 experiments (listed in table) 


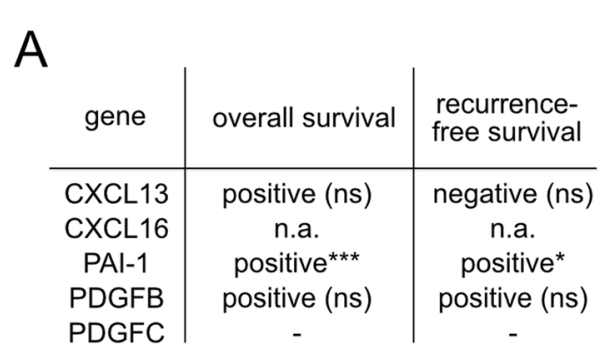

C
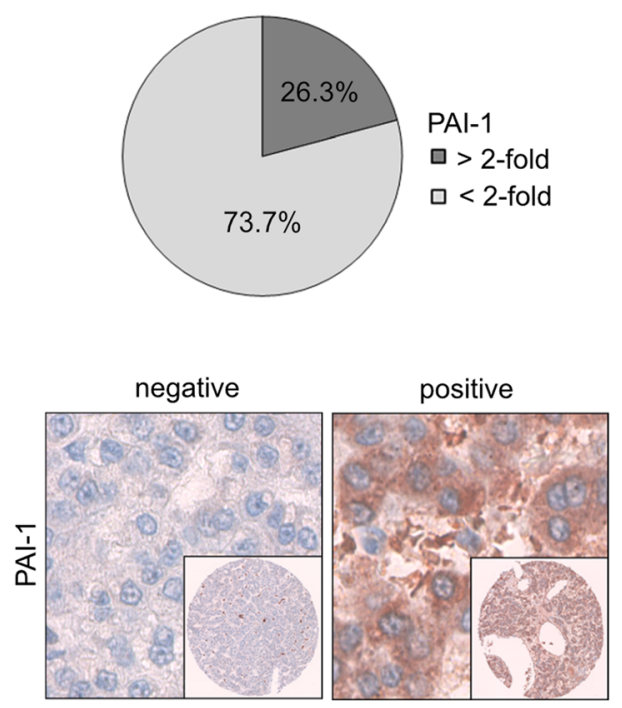

B
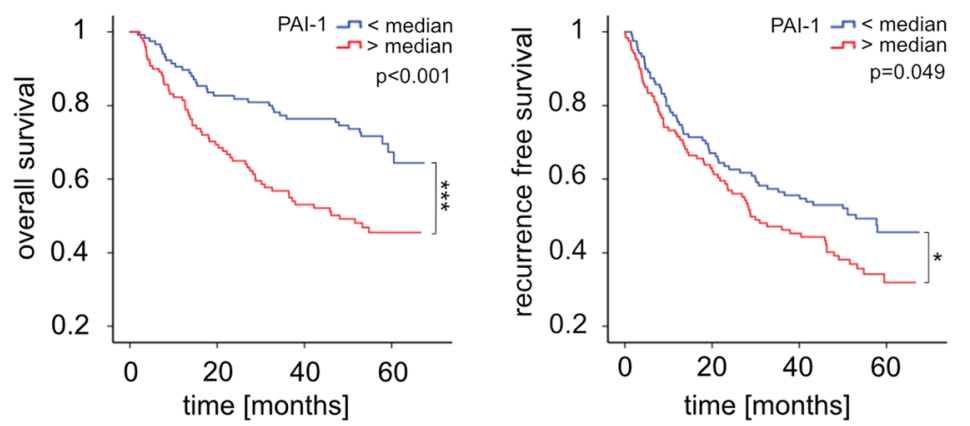

D
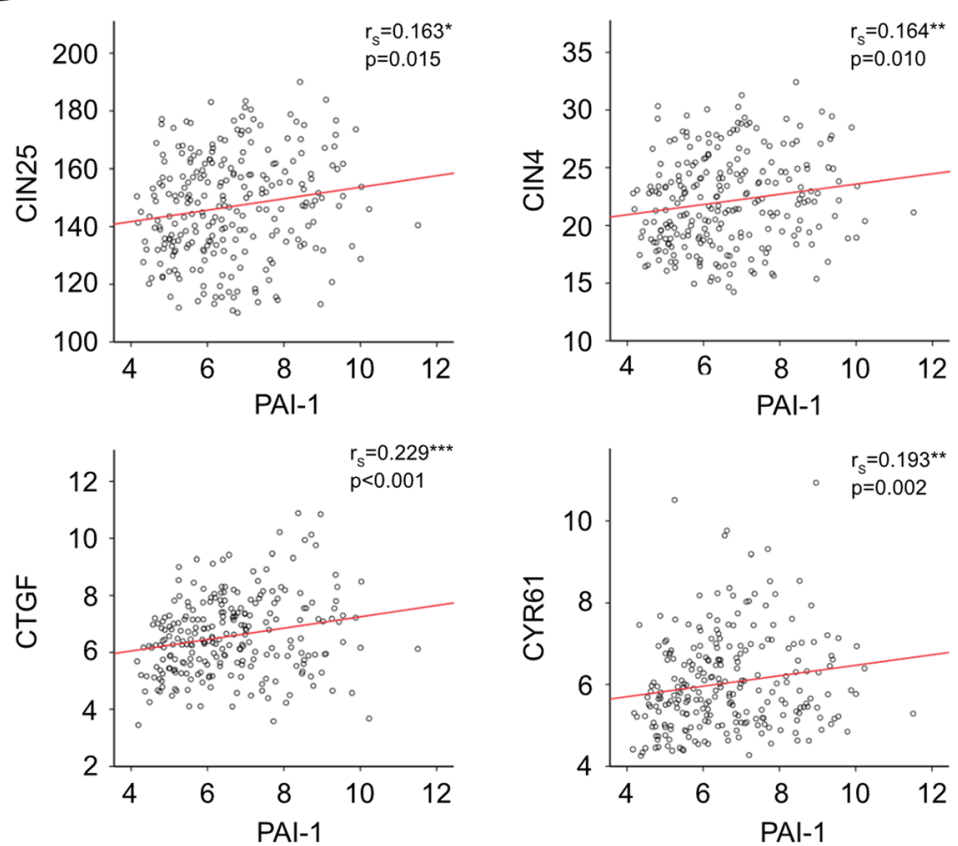

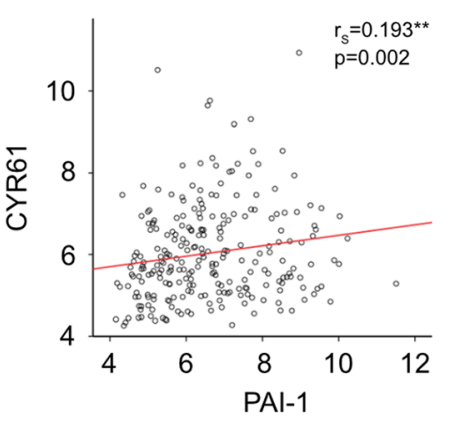

Fig. 3 PAl-1 expression in HCC tissues associates with poor clinical outcome and YAP target gene expression. a Table summarizing the results of patient sample analysis. Positive: high level expression positively associates with poor clinical outcome; negative: high level expression negatively associates with poor clinical outcome. Transcriptome data were derived from $242 \mathrm{HCC}$ patients. ns - no significant difference, ${ }^{*} p \leq 0.05,{ }^{* * *} p \leq$ 0.001. Statistical test: log-rank test. b Overall survival and cancer recurrence of HCC patients with high or low PAl-1 transcript levels are shown by Kaplan-Meier curves. ${ }^{*} p \leq 0.05,{ }^{* * *} p \leq 0.001$. Statistical test: log-rank test. $\mathbf{c}$ Pie chart illustrating $\geq 2$-fold PAl-1 overexpression at the mRNA level in HCC patient samples compared to corresponding normal tissue (real-time PCR). In the lower part, exemplary immunohistochemical stains of HCC tissues with low or high PAl-1 expression are shown (TMA analysis). $\mathbf{d}$ Association between PAl-1 expression and YAP-induced gene signatures (CIN4/CIN25) as well as YAP target genes CTGF and CYR61 in human HCC tissues is shown. ${ }^{*} p \leq 0.05,{ }^{* *} p \leq 0.01,{ }^{* * *} p \leq 0.001$. Statistical test: Spearman correlation $\left(r_{s}\right)$

YAP-induced PAI-1 controls expression of genes involved in cellular senescence

To dissect how PAI-1 could contribute to YAP-driven tumorigenesis, expression profiling of Sk-Hep1 cells after PAI-1 inhibition was performed (scr. vs. siPAI-1). In total, 3174 mRNAs were significantly regulated after PAI-1 inhibition compared to control siRNA-transfected cells (at least $+/-1.3$-fold change). While 1283 genes were upregulated (negatively regulated by PAI-1), 1891 transcripts were reduced (positively regulated by PAI-1).
Interestingly, a gene set enrichment analysis (GSEA) revealed a significant enrichment of regulated genes in the process 'cellular senescence' (NES: - 1.77 and FDR = 0.002), (Fig. 5a/b). Indeed, the senescence-associated secretory phenotype (SASP) is characterized by the regulation of growth factors and chemokines as observed in our mouse model [14]. Accordingly, genes associated with SASP such as insulin-like growth factor binding protein-3 (IGFBP3) or factors characteristic for replicative senescence (e.g. checkpoint kinase-1; CHK1) were 


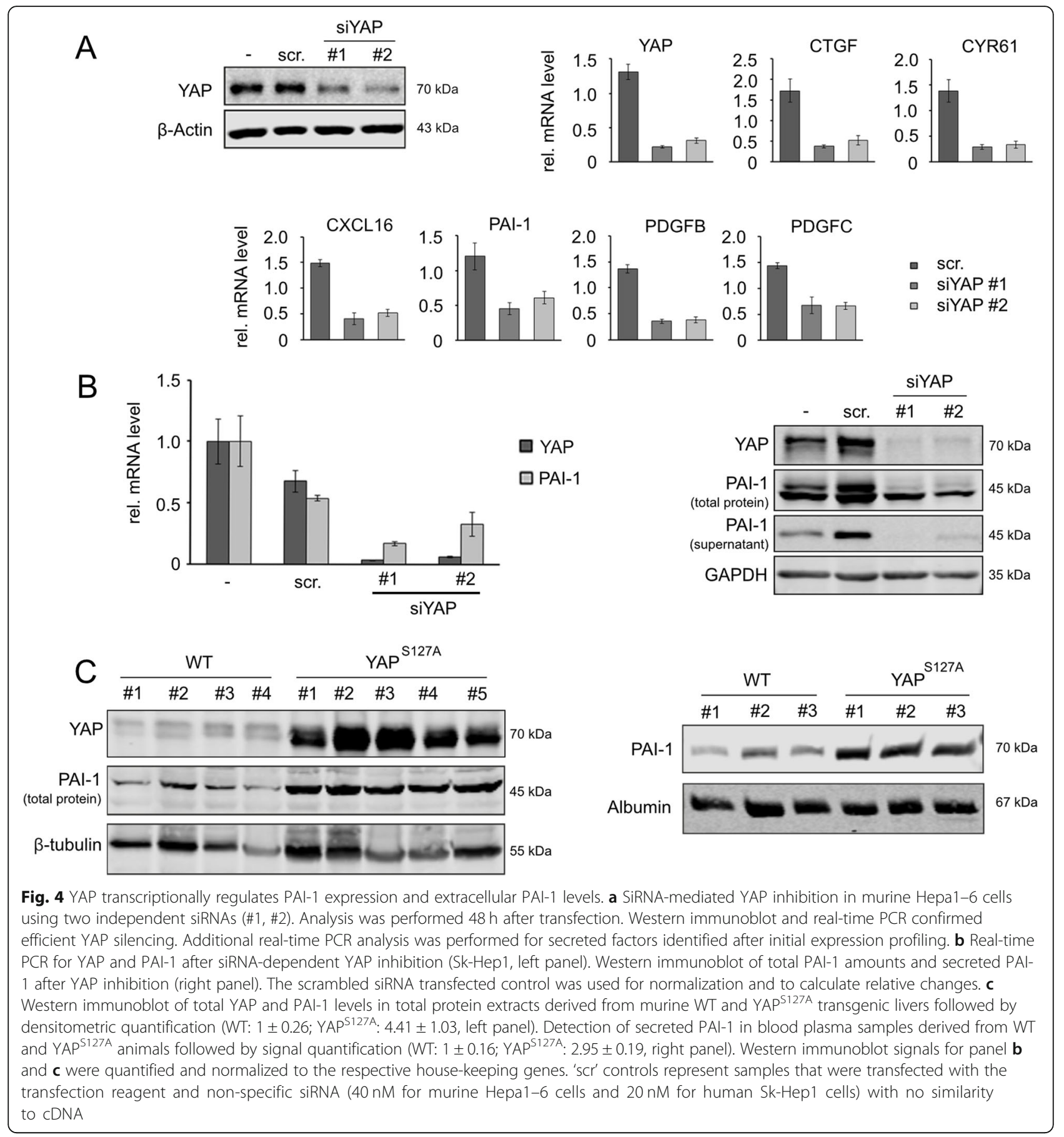

repressed after PAI-1 silencing (Fig. 5c). Although the precise molecular mechanism of how PAI-1 controls transcriptional changes of these factors remains unclear, a potential role of PAI-1 in the regulation of senescence has already been discussed for other cell types $[14,15]$.

Because our data illustrated that YAP-regulated PAI-1 might affect cellular senescence, we investigated in the next step if a senescence-associated phenotype was detectable after $\mathrm{YAP}^{\mathrm{S} 127 \mathrm{~A}}$ overexpression in vivo. In tumor nodules derived from $\mathrm{YAP}^{\mathrm{S} 127 \mathrm{~A}}$ transgenic mice, elevated YAP and PAI-1 levels were observed (Fig. 5d). Additionally, positivity of the senescence marker $B$-galactosidase was only measurable in $\mathrm{YAP}^{\mathrm{S127A}}$-positive samples but not in WT liver tissues.

Together, these results strongly suggest that YAPinduced PAI-1 contributes to an oncogene-induced senescence phenotype. 


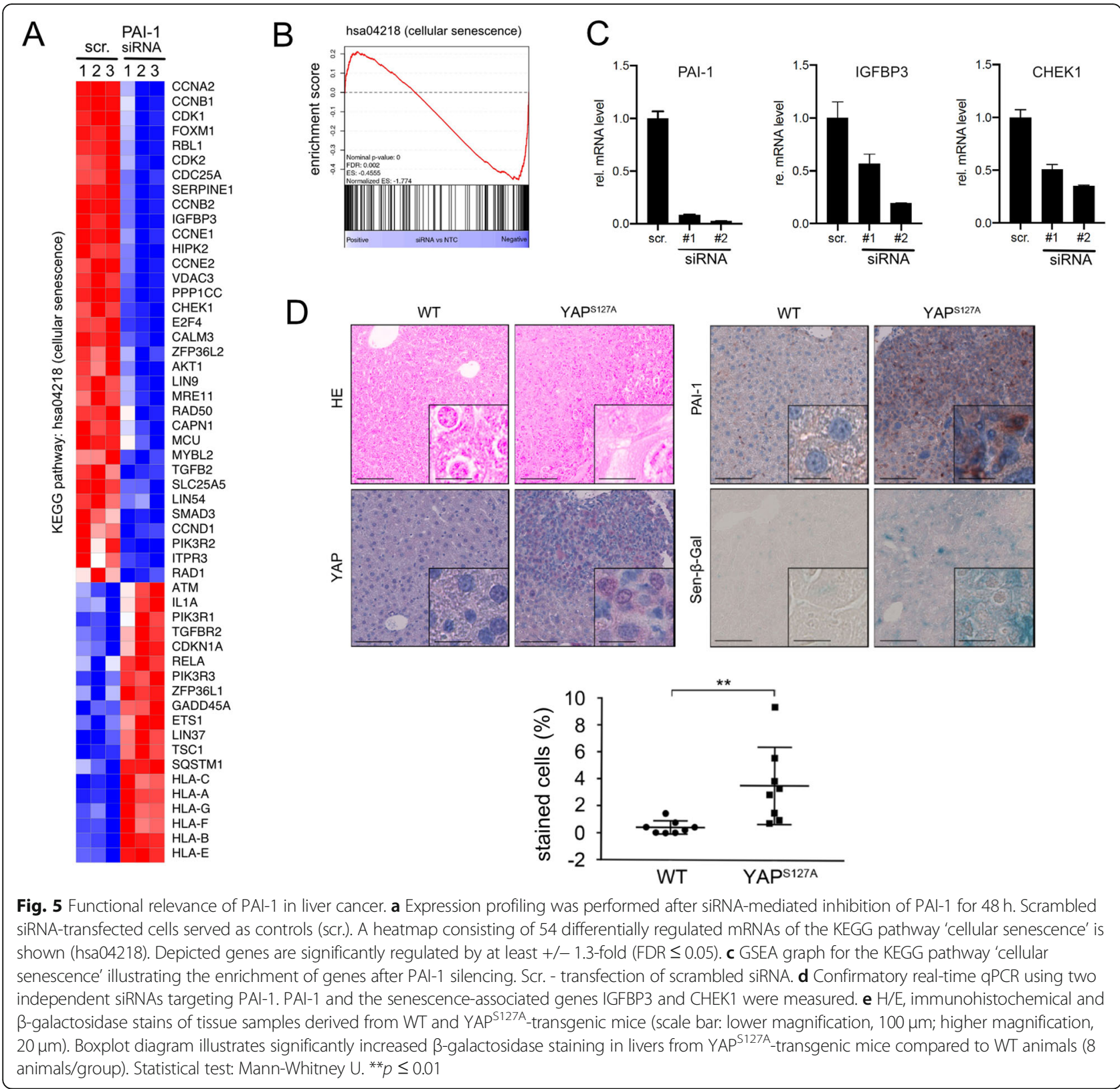

\section{The YAP/TEAD4 protein complex regulates PAI-1}

\section{expression}

Lastly, we aimed to understand the molecular mechanism how YAP controls PAI-1 expression. Because YAP is a transcriptional co-activator that does not contain a DNA binding site, it physically interacts with several transcription factors (TFs) to control target gene transcription. To define the precise mechanism how YAP regulates PAI-1, different known YAP-interacting TFs such as TEAD1, TEAD4 and FOXM1 were inhibited by RNAi and the effect on PAI-1 expression was analyzed $[3,16,17]$.

Silencing of TEAD4 but not of TEAD1 or FOXM1 was associated with reduced PAI-1 transcript levels
(Fig. 6a). In addition, protein expression and secretion were diminished after TEAD4 inhibition (total PAI-1: down to 45\%; secreted PAI-1: down to $43 \%$, Fig. $6 \mathrm{~b}$ ). To further substantiate these results, Verteporfin was administered, which is known to disrupt the TEAD/ YAP complex followed by degradation of YAP [18]. Indeed, YAP degradation was associated with reduced PAI-1 levels in cell lysates and cell culture supernatants after Verteporfin treatment in a concentrationdependent manner (total PAI-1: down to 79\%; secreted PAI-1: down to 20\%, Fig. 6c).

In the next step, we tested whether TEAD4 and YAP directly bind to the PAI-1 promoter of murine Hepa1-6 and human Sk-Hep1 cells. To identify 

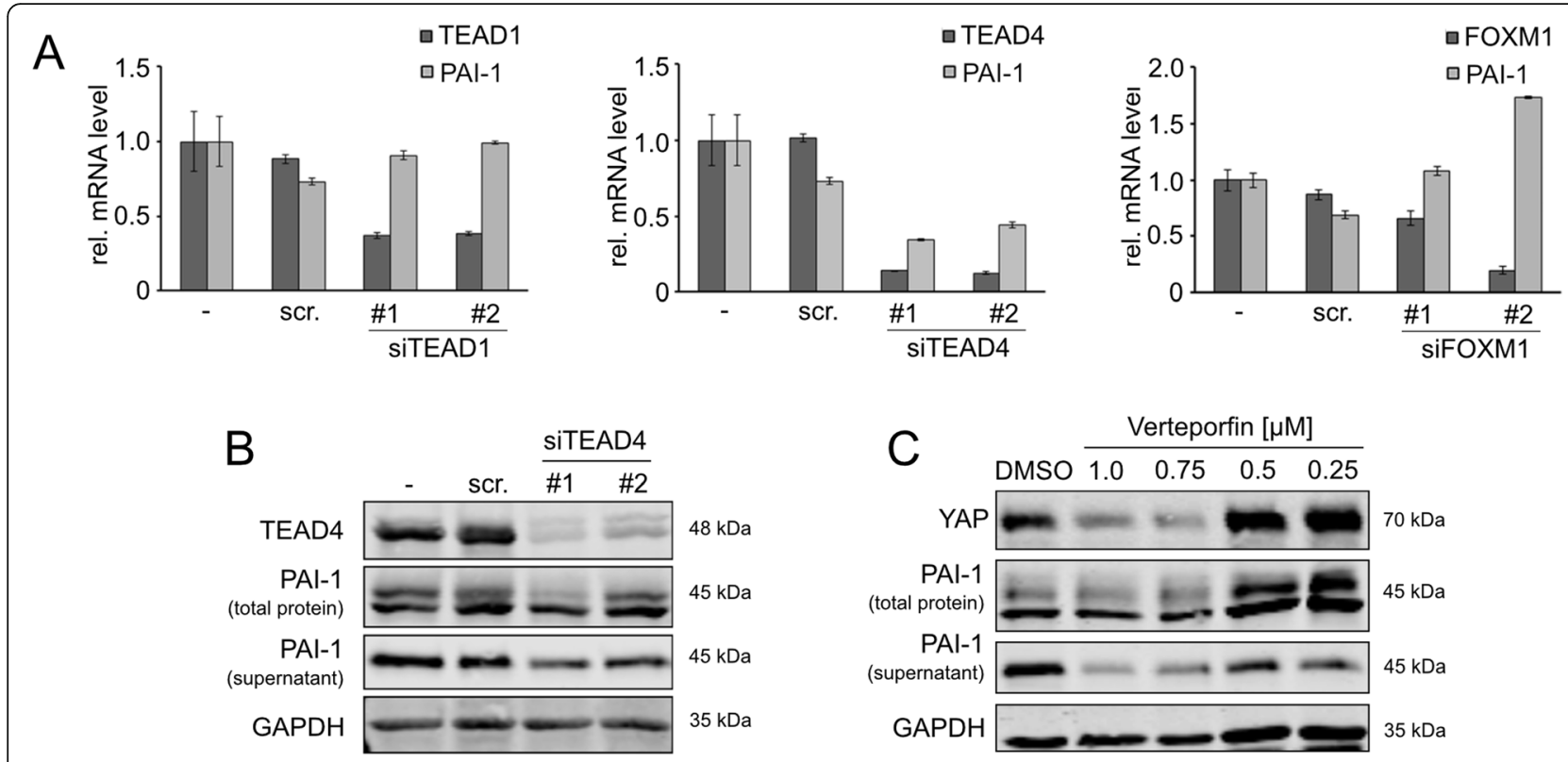

Fig. 6 PAl-1 expression is regulated by the YAP/TEAD4 complex. a Real-time PCR analysis of PAl-1 mRNA levels after siRNA-mediated silencing of the known YAP-interacting transcription factors TEAD1, TEAD4 and FOXM1. Two independent siRNAs for each transcription factor were used (\#1, \#2) and compared to untreated (-) and scrambled siRNA-transfected SNU-182 cells (scr.). b Protein detection of secreted PAl-1 levels in the supernatant and total protein fractions derived from cultured Sk-Hep1 cells after siRNA mediated TEAD4-Inhibition. c Liver cancer cell line Sk-Hep1 was treated with increasing Verteporfin concentrations $(0.25-1.0 \mu \mathrm{M})$ for $24 \mathrm{~h}$ followed by the detection of intracellular and secreted PAl-1. For $\mathbf{b}$ and $\mathbf{c}$, signal intensity was measured and normalized to GAPDH. 'scr' controls represent samples that were transfected with the transfection reagent and non-specific siRNA $(40 \mathrm{nM})$ with no similarity to CDNA

potential TEAD4-binding sites, the JASPAR database was screened for promising sites in the PAI-1 gene (SERPINE1) and compared to publicly available TEAD4 ChIP-sequencing data sets of cancer cell lines $[12,19]$. As a result, putative binding sites of TEAD4 were identified within the second exon of the murine PAI-1 gene and within the first exon of the human PAI-1 gene (see schemes Fig. 7a, left panel). Chromatin immunoprecipitation (ChIP) analysis illustrated binding of TEAD4 and YAP to the predicted binding sites in both analyzed cell lines, while significantly lower binding was observed for control regions downstream of the specific binding sites (Fig. 7a, right panel).

ChIP results were confirmed by a luciferase reporter assay showing that siRNA-mediated silencing of YAP or TEAD4 diminished reporter gene expression, which was under the control of the SERPINE1 promoter region containing the TEAD4 binding site (Fig. 7b). Equally, a point mutation in the TEAD4 binding site reduced luciferase expression about $45 \%$ compared to the wildtype site (Fig. 7c).

In summary, these results demonstrate the direct transcriptional regulation of PAI-1 by the YAP/TEAD4 complex as one mechanism responsible for increased PAI-1 secretion after YAP activation.

\section{Discussion}

Based on transcriptomic and proteomic screening, this study illustrates that the oncogene YAP induces a secretory phenotype in liver tumorigenesis. Recent research demonstrates that an intense heterologous communication between liver resident cells such as hepatocytes, hepatic stellate cells, endothelial cells and Kupffer cells is required for tissue development, maintenance and regeneration [20]. Dysregulation of these multi-cellular communication networks can contribute to chronic liver diseases and tumorigenesis as illustrated for Notch1 signaling and its impact on tumor cell dissemination [21]. However, secreted factors may also affect neighboring cells already in premalignant conditions to reprogram their cellular functions or to create a tumor-supporting microenvironment [22]. To understand this heterologous secretome network and to identify promising points of interference for the development of therapeutic strategies, it is essential to decipher communication patterns connecting identical and different cell types in tumorigenesis.

For the Hippo signaling pathway, we here show that YAP regulates the secretion of chemokines and cytokines which are detectable in blood samples of $\mathrm{YAP}^{\mathrm{S} 127 \mathrm{~A}}$ transgenic mice as illustrated for CXCL13, CXCL16 and PAI-1. On one hand, these factors represent potential 

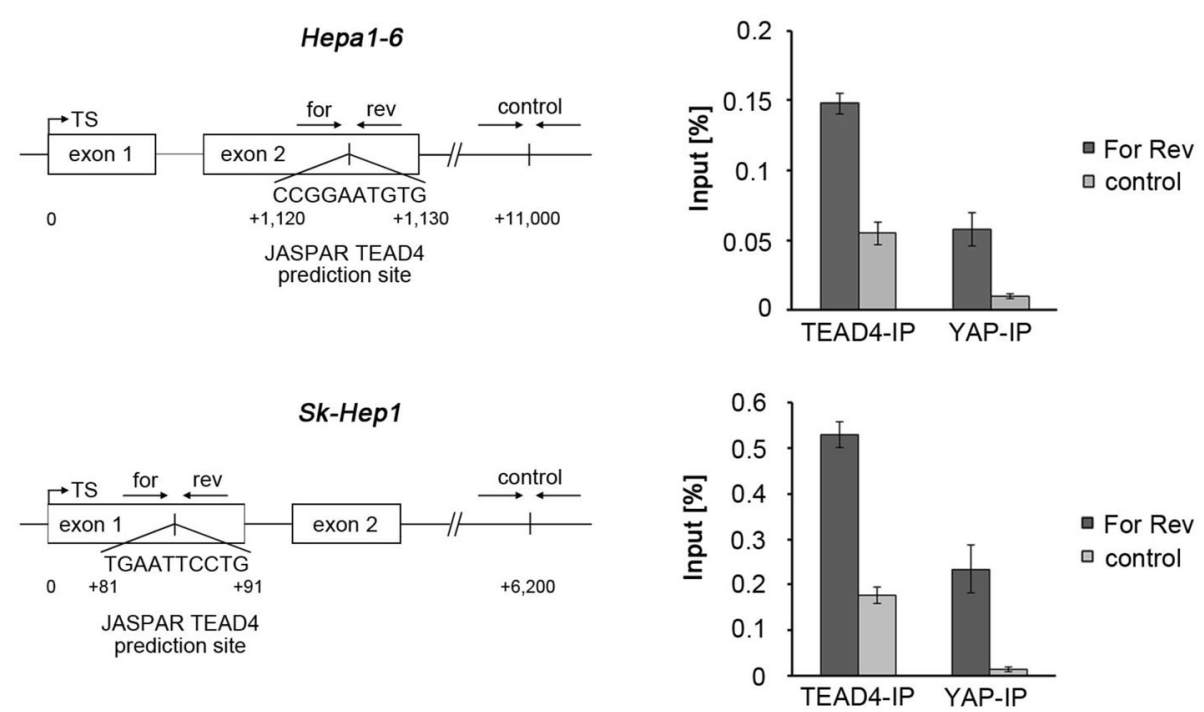

Fig. 7 YAP and TEAD4 interact with the SERPINE1 promoter. a ChIP analysis of TEAD4 and YAP binding to the murine (Hepa1-6) and human (Sk-Hep1) SERPINE1 promoters at the indicated binding sites predicted by the JASPAR database. Schemes illustrate the potential binding sites and the downstream control site. TS - transcriptional start. Bars illustrate the relative binding capacity at the respective site in relation to the total input. b Luciferase assay after transient transfection of HEK-293 cells with pGL3-PAI-1 with and without siRNA-mediated inhibition of YAP or TEAD4 (2 siRNAs for each gene were tested). scr. - scrambled siRNA served as control. Coexpression of pRL-CMV-Renilla vector was used for normalization. c Coexpression of pGL3 (containing wildtype and mutated TEAD4 binding sites), pRL-CMV-Renilla (all samples, for normalization) and PDEST (with and without YAP) in HEK-293 cells

communication hubs that connect YAP-overexpressing hepatocytes with other cells types such as infiltrating immune cells (e.g. CXCL13 stimulates IgG secretion by B cells or CXCL16-guided recruitment of NKT cells [23, 24];). On the other hand, secreted bioactive proteins may serve as biomarkers to identify groups of patients that are suitable for targeted therapy. In case of the Hippo pathway, specific gene cytokine/chemokine/ growth factor signatures in the blood serum or plasma could characterize cancer patient groups that would benefit from a YAP-targeted therapy [1]. For example, elevated concentrations of proteins (e.g. PAI-1, CXCL13 and CXCL16) in the blood could indicate YAP activation in HCC tumor cells, which is detectable in about $30 \%$ of all HCC cases [3]. This risk-free and non-invasive method could guide clinicians to administer drugs and drug combinations in the future that include specific inhibitors for YAP $[18,25]$.

Indeed, approaches for the activation of the Hippo pathway and especially the inactivation of its negatively regulated downstream effector YAP are currently intensely investigated. First recently presented small compounds developed by different companies have been proposed as potential lead-compounds since they change YAP reporter assays, directly disturb physical interaction between YAP and TEADs [25], or change TEAD activity in a dominant-negative manner [26]. Our results indicate, that alternative treatment strategies could focus on communication networks induced by YAP in tumorigenesis. Here, perturbation of YAP-dependent intercellular communication (including PAI-1 as discussed below) could lead to a normalization of the tumor microenvironment, reduced tumor progression or even regression.

The protein PAI-1 drew our special attention, since it was not only clearly regulated by YAP in blood plasma samples in vivo but its expression was also significantly associated with poor clinical outcome. Like CTGF and CYR61, PAI-1 has already been described as regulated by YAP and Yorki (the YAP orthologue in Drosophila melanogaster) by high-throughput screening approaches [27], however, to our knowledge this is the first report demonstrating YAP/TEAD-dependent transcriptional regulation and secretion of PAI-1. PAI-1, which is encoded by the SERPINE1 gene, acts as inhibitor of tissue plasminogen activator (tPA) and urokinase plasminogen activator (uPA) and has been described to correlate with poor patient prognosis of different tumor types including breast cancer $[28,29]$. On the one hand, the prognostic relevance of PAI-1 overexpression may be related to its inhibitory effect on profibrinolytic plasmin associated with hypo-fibrinolytic conditions, which is commonly seen in patients with liver malignancies with venous thromboembolic complications [30]. On the other hand, PAI-1 expression has been described to modulate cancer cell proliferation and support tumorigenesis through its pro-angiogenic, pro-migratory and anti-apoptotic effects [15]. In addition, more recent data 
also demonstrates that PAI-1 controls cellular senescence and immune cell functionality as illustrated for macrophage migration and polarization [31-33].

Interestingly, no significant effect on cell viability, proliferation or migration were detectable after PAI-1 inhibition in our study (data not shown). It is therefore likely that further (YAP-induced) factors cooperating with PAI-1 are required to induce a prominent proliferative response. Instead, our data suggest that YAP-induced PAI-1 contributes to oncogene-induced senescence in vitro and in vivo. At first glance this seems contradicting since cellular senescence is considered to be a tumorsuppressive mechanism protecting cells from malignant transformation upon extra- or intracellular stress [34]. However, next to its safeguarding function, cellular senescence can also facilitate deleterious properties. This phenotype is characterized by SASP, consisting of actively secreted growth factors and chemokines [14]. These soluble signaling factors affect tumor and non-neoplastic cells to create a tumor-supportive microenvironment. The idea that YAP-dependent PAI-1 expression contributes to senescence is supported by previous data showing that in other experimental model systems PAI-1 is not only a bystander but also can stimulate replicative senescence [33]. Further studies are needed to decipher the specific role of PAI-1 in the context of SASP and its connection to YAP activation.

Due to its multiple tumor-promoting properties in several tumor entities, PAI-1 has also been considered as therapeutic target structure and several small compounds or antibodies specifically blocking PAI-1 activity have been developed [15, 35]. Some of these substances showed promising results in vitro and in vivo such as SK-116, which reduced serum PAI-1 levels and the number of intestinal polyps in mice with APC mutations [36]. However, no PAI-1-specific therapy has been tested in clinical trials, which is partly due to low stability of inhibitors and required high drug concentrations [15, 37]. Currently, it is questionable if therapies that exclusively target PAI-1 will be available, soon. Instead, combinatory silencing of PAI-1 together with other YAP-dependent secreted factors, may slow down tumor progression. One example for this kind of cooperative treatment is Maraviroc, which blocks the chemokine (C-C motif) receptor 5 (CCR5) that is activated by YAP-dependent CXCL13 [38]. It will be interesting to investigate if also the other identified secreted factors such as CXCL13 or CXCL16 are directly regulated by the YAP/TEAD4 complex or if additional YAP-interacting transcription factors such as FOXM1 or p73 contribute to the secretory phenotype observed in YAP-transgenic mice $[3,16,39]$.
Although, the present study clearly illustrates that oncogenic YAP directly controls PAI-1 expression, the molecular impact on the other identified secreted factors such as CXCL13, CXCL16, PDGFB and PDGFC is less clear. Future studies not only must clarify if the YAP/TEAD complex directly controls transcription of the cytokines but also how consistent these effects are in different HCC cells or other tumor entities. This would be of special importance since the results will illustrate if PAI-1 and other cytokines could also serve as biomarkers or therapeutic target structures.

\section{Conclusions}

This study illustrates that YAP-overexpressing hepatocytes and HCC cells control the expression of several paracrine-acting factors as exemplified for PAI-1. YAP is therefore responsible for a secretory phenotype that could connect tumorous and non-tumorous cell types in chronic liver disease and tumorigenesis. A comprehensive understanding of these communication networks will serve as basis to develop biomarkers and therapies targeting these points-of-interference with the aim to normalize heterologous communication patterns.

\section{Supplementary information}

Supplementary information accompanies this paper at https://doi.org/10. 1186/s12964-020-00634-6.

Additional file 1. Supplementary Tables S1-S4 and Supplementary Table S5).

\begin{abstract}
Abbreviations
ChIP: Chromatin immunoprecipitation; CIN: Chromosome instability; CXCL13: C-X-C motif chemokine ligand 13; CXCL16: C-X-C motif chemokine ligand 16; CTGF: Connective tissue growth factor; CYR61: Cysteine-rich angiogenic inducer 61; ECM: Extracellular matrix; HCC: Hepatocellular carcinoma; PAl-1: Plasminogen activator inhibitor-1; RNAi: RNAinterference; SASP: Senescence-associated secretory phenotype; TEAD: TEA domain transcription factor; YAP: Yes-associated protein
\end{abstract}

\section{Acknowledgements}

The authors thank Jennifer Schmitt for excellent technical assistance. We thank the Center of Model System and Comparative Pathology (CMCP; Dr. T. Poth, D. Lutz and H. Conrad) for their support.

\section{Authors' contributions \\ SM, ST, MB, TL, and CDLT performed the experiments. ST, SMEW, CT, NG analyzed and interpreted the data. MT, ST, BKS, JM and PS performed histological evaluation of tissue samples. SM, ST, SMEW, and KB wrote the manuscript. All authors read and approved the final manuscript.}

\section{Authors' information}

Not applicable.

\section{Funding}

This study was supported by a grant from the German Cancer Aid (Deutsche Krebshilfe/Dr. Mildred Scheel Stiftung, DKH 111524 to KB and DKH 70112669 to SM) and the SFB/TR 209 "Liver Cancer" (314905040 to KB, PS). Open access funding provided by Projekt DEAL. 


\section{Availability of data and materials}

Transcriptome data generated and/or analyzed during the current study are available in the GEO database (GSE128043 for primary hepatocytes and GSE150796 for PAl-1 inhibition in Sk-Hep1 cells). The remaining data generated and analyzed during the current study are available from the corresponding author on reasonable request.

\section{Ethics approval and consent to participate}

Human HCC cases were surgically resected at the University Hospital of Heidelberg and histologically classified by two experienced pathologists based on established criteria. Human tissue samples were provided by the Tissue Bank of the National Center of Tumor Diseases (NCT, Heidelberg, Germany) in accordance with the regulations of the Tissue Bank and the approval of the Ethics Committee of Heidelberg University (application no. 206/05). Human HCC cases were surgically resected at the University Hospital of Mainz and histologically classified $(n=19)$. The study was approved by the institutional ethics committee of the Landesärztekammer Rheinland Pfalz (837.146.17: 10980).

Animal work was authorized by the German Regional Council of BadenWürttemberg (Regierungspräsidium Karlsruhe) according to the EU directive 2010/63EU. All experiments were performed in accordance with the institutional regulations of the IBF (Interfakultäre Biomedizinische Forschungseinrichtung, University of Heidelberg) under pathogen-free (SPF) conditions. The mouse colony was housed under a $12 \mathrm{~h}$ light/dark cycle with free access to water and food. Exclusion and termination criteria were defined in the ATBW criteria.

\section{Consent for publication}

Not applicable.

\section{Competing interests}

The authors declare that they have no competing interests.

\section{Author details}

1 Institute of Pathology, University Hospital Heidelberg, Heidelberg, Germany.

2Present address: Department of Medicine II, LMU Munich, Munich, Germany.

${ }^{3}$ Medical Faculty Mannheim, Medical Research Center, University of Heidelberg, Mannheim, Germany. ${ }^{4}$ Institute of Pathology, Johannes Gutenberg University, Mainz, Germany. ${ }^{5}$ Department of Medicine I, Johannes Gutenberg University, Mainz, Germany. ${ }^{6}$ Present address: Department of Medicine I, University Hospital Lübeck, Lübeck, Germany.

Received: 10 March 2020 Accepted: 31 July 2020

Published online: 23 October 2020

\section{References}

1. Johnson R, Halder G. The two faces of hippo: targeting the hippo pathway for regenerative medicine and cancer treatment. Nat Rev Drug Discov. 2014; 13:63-79.

2. Patel SH, Camargo FD, Yimlamai D. Hippo signaling in the liver regulates organ size, cell fate, and carcinogenesis. Gastroenterology. 2017;152:533-45.

3. Weiler SME, Pinna F, Wolf T, Lutz T, Geldiyev A, Sticht C, Knaub M, Thomann S, Bissinger M, Wan S, et al. Induction of chromosome instability by activation of yes-associated protein and Forkhead box M1 in liver Cancer. Gastroenterology. 2017;152:2037-51 e2022.

4. Lee KP, Lee JH, Kim TS, Kim TH, Park HD, Byun JS, Kim MC, Jeong WI, Calvisi DF, Kim JM, Lim DS. The hippo-Salvador pathway restrains hepatic oval cell proliferation, liver size, and liver tumorigenesis. Proc Natl Acad Sci U S A. 2010;107:8248-53.

5. Song H, Mak KK, Topol L, Yun K, Hu J, Garrett L, Chen Y, Park O, Chang J, Simpson RM, et al. Mammalian Mst1 and Mst2 kinases play essential roles in organ size control and tumor suppression. Proc Natl Acad Sci U S A. 2010; 107:1431-6.

6. Tschaharganeh DF, Chen X, Latzko P, Malz M, Gaida MM, Felix K, Ladu S, Singer S, Pinna F, Gretz N, et al. Yes-associated protein up-regulates Jagged1 and activates the notch pathway in human hepatocellular carcinoma. Gastroenterology. 2013;144:1530-42 e1512.

7. Weiler SME, Lutz T, Bissinger M, Sticht C, Knaub M, Gretz N, Schirmacher P, Breuhahn K. TAZ target gene ITGAV regulates invasion and feeds back positively on YAP and TAZ in liver cancer cells. Cancer Lett. 2020;473:164-75.
8. Yabuta N, Mukai S, Okamoto A, Okuzaki D, Suzuki H, Torigata K, Yoshida K, Okada N, Miura D, Ito A, et al. N-terminal truncation of Lats1 causes abnormal cell growth control and chromosomal instability. J Cell Sci. 2013; 126:508-20.

9. Zhou TY, Zhou YL, Qian MJ, Fang YZ, Ye S, Xin WX, Yang XC, Wu HH. Interleukin-6 induced by YAP in hepatocellular carcinoma cells recruits tumor-associated macrophages. J Pharmacol Sci. 2018;138:89-95.

10. Camargo FD, Gokhale S, Johnnidis JB, Fu D, Bell GW, Jaenisch R, Brummelkamp TR. YAP1 increases organ size and expands undifferentiated progenitor cells. Curr Biol. 2007;17:2054-60.

11. Vandesompele J, De Preter K, Pattyn F, Poppe B, Van Roy N, De Paepe A, Speleman F. Accurate normalization of real-time quantitative RT-PCR data by geometric averaging of multiple internal control genes. Genome Biol. 2002;3:RESEARCH0034

12. Mathelier A, Zhao X, Zhang AW, Parcy F, Worsley-Hunt R, Arenillas DJ, Buchman S, Chen CY, Chou A, lenasescu H, et al. JASPAR 2014: an extensively expanded and updated open-access database of transcription factor binding profiles. Nucleic Acids Res. 2014;42:D142-7.

13. Roessler S, Jia HL, Budhu A, Forgues M, Ye QH, Lee JS, Thorgeirsson SS, Sun $Z$, Tang $Z Y$, Qin LX, Wang XW. A unique metastasis gene signature enables prediction of tumor relapse in early-stage hepatocellular carcinoma patients Cancer Res. 2010;70:10202-12.

14. Coppe JP, Desprez PY, Krtolica A, Campisi J. The senescence-associated secretory phenotype: the dark side of tumor suppression. Annu Rev Pathol. 2010:5:99-118.

15. Kubala MH, DeClerck YA. The plasminogen activator inhibitor-1 paradox in cancer: a mechanistic understanding. Cancer Metastasis Rev. 2019;38: 483-92.

16. Eisinger-Mathason TS, Mucaj V, Biju KM, Nakazawa MS, Gohil M, Cash TP, Yoon SS, Skuli N, Park KM, Gerecht S, Simon MC. Deregulation of the hippo pathway in soft-tissue sarcoma promotes FOXM1 expression and tumorigenesis. Proc Natl Acad Sci U S A. 2015;112:E3402-11.

17. Zhao B, Ye X, Yu J, Li L, Li W, Li S, Yu J, Lin JD, Wang CY, Chinnaiyan AM, et al. TEAD mediates YAP-dependent gene induction and growth control. Genes Dev. 2008;22:1962-71.

18. Liu-Chittenden Y, Huang B, Shim JS, Chen Q, Lee SJ, Anders RA, Liu JO, Pan D. Genetic and pharmacological disruption of the TEAD-YAP complex suppresses the oncogenic activity of YAP. Genes Dev. 2012;26:1300-5.

19. Encode Project Consortium. An integrated encyclopedia of DNA elements in the human genome. Nature. 2012;489:57-74.

20. Camp JG, Sekine K, Gerber T, Loeffler-Wirth H, Binder H, Gac M, Kanton S, Kageyama J, Damm G, Seehofer D, et al. Multilineage communication regulates human liver bud development from pluripotency. Nature. 2017; 546:533-8.

21. Wieland E, Rodriguez-Vita J, Liebler SS, Mogler C, Moll I, Herberich SE, Espinet E, Herpel E, Menuchin A, Chang-Claude J, et al. Endothelial Notch1 activity facilitates metastasis. Cancer Cell. 2017;31:355-67.

22. Nussbaum T, Samarin J, Ehemann V, Bissinger M, Ryschich E, Khamidjanov A, Yu X, Gretz N, Schirmacher P, Breuhahn K. Autocrine insulin-like growth factor-ll stimulation of tumor cell migration is a progression step in human hepatocarcinogenesis. Hepatology. 2008;48:146-56.

23. Geissmann F, Cameron TO, Sidobre S, Manlongat N, Kronenberg M, Briskin MJ, Dustin ML, Littman DR. Intravascular immune surveillance by CXCR6+ NKT cells patrolling liver sinusoids. PLoS Biol. 2005;3:e113.

24. Li C, Kang D, Sun X, Liu Y, Wang J, Gao P. The effect of C-X-C motif chemokine 13 on hepatocellular carcinoma associates with Wnt signaling. Biomed Res Int. 2015;2015:345413.

25. Calses PC, Crawford JJ, Lill JR, Dey A. Hippo pathway in Cancer: aberrant regulation and therapeutic opportunities. Trends Cancer. 2019;5:297-307.

26. Holden JK, Crawford JJ, Noland CL, Schmidt S, Zbieg JR, Lacap JA, Zang R, Miller GM, Zhang Y, Beroza P, et al. Small molecule Dysregulation of TEAD Lipidation induces a dominant-negative inhibition of hippo pathway signaling. Cell Rep. 2020;31:107809.

27. Liu F, Lagares D, Choi KM, Stopfer L, Marinkovic A, Vrbanac V, Probst CK, Hiemer SE, Sisson TH, Horowitz JC, et al. Mechanosignaling through YAP and TAZ drives fibroblast activation and fibrosis. Am J Physiol Lung Cell Mol Physiol. 2015;308:L344-57.

28. Li S, Wei $X$, He J, Tian $X$, Yuan S, Sun L. Plasminogen activator inhibitor-1 in cancer research. Biomed Pharmacother. 2018;105:83-94.

29. Palmirotta R, Ferroni P, Savonarola A, Martini F, Ciatti F, Laudisi A, Sini V, Del Monte G, Guadagni F, Roselli M. Prognostic value of pre-surgical plasma 
PAl-1 (plasminogen activator inhibitor-1) levels in breast cancer. Thromb Res. 2009;124:403-8.

30. Carmeliet P, Stassen JM, Schoonjans L, Ream B, van den Oord JJ, De Mol M, Mulligan RC, Collen D. Plasminogen activator inhibitor-1 gene-deficient mice. II. Effects on hemostasis, thrombosis, and thrombolysis. J Clin Invest. 1993;92:2756-60.

31. Ichimura A, Matsumoto S, Suzuki S, Dan T, Yamaki S, Sato Y, Kiyomoto H, Ishii N, Okada K, Matsuo O, et al. A small molecule inhibitor to plasminogen activator inhibitor 1 inhibits macrophage migration. Arterioscler Thromb Vasc Biol. 2013;33:935-42.

32. Kubala MH, Punj V, Placencio-Hickok VR, Fang H, Fernandez GE, Sposto R, DeClerck YA. Plasminogen activator Inhibitor-1 promotes the recruitment and polarization of macrophages in Cancer. Cell Rep. 2018;25:2177-91 e2177.

33. Kortlever RM, Higgins PJ, Bernards R. Plasminogen activator inhibitor-1 is a critical downstream target of p53 in the induction of replicative senescence. Nat Cell Biol. 2006;8:877-84.

34. Campisi J. d'Adda di Fagagna F: cellular senescence: when bad things happen to good cells. Nat Rev Mol Cell Biol. 2007;8:729-40.

35. Rouch A, Vanucci-Bacque C, Bedos-Belval F, Baltas M. Small molecules inhibitors of plasminogen activator inhibitor-1 - an overview. Eur J Med Chem. 2015:92:619-36.

36. Mutoh M, Niho N, Komiya M, Takahashi M, Ohtsubo R, Nakatogawa K, Ueda K, Sugimura T, Wakabayashi K. Plasminogen activator inhibitor-1 (Pai-1) blockers suppress intestinal polyp formation in min mice. Carcinogenesis. 2008;29:824-9.

37. Gorlatova NV, Cale JM, Elokdah H, Li D, Fan K, Warnock M, Crandall DL, Lawrence DA. Mechanism of inactivation of plasminogen activator inhibitor1 by a small molecule inhibitor. J Biol Chem. 2007;282:9288-96.

38. Pervaiz A, Zepp M, Mahmood S, Ali DM, Berger MR, Adwan H. CCR5 blockage by maraviroc: a potential therapeutic option for metastatic breast cancer. Cell Oncol (Dordr). 2019;42:93-106.

39. Strano S, Monti O, Pediconi N, Baccarini A, Fontemaggi G, Lapi E, Mantovani F, Damalas A, Citro G, Sacchi A, et al. The transcriptional coactivator yesassociated protein drives p73 gene-target specificity in response to DNA damage. Mol Cell. 2005;18:447-59.

\section{Publisher's Note}

Springer Nature remains neutral with regard to jurisdictional claims in published maps and institutional affiliations.

Ready to submit your research? Choose BMC and benefit from:

- fast, convenient online submission

- thorough peer review by experienced researchers in your field

- rapid publication on acceptance

- support for research data, including large and complex data types

- gold Open Access which fosters wider collaboration and increased citations

- maximum visibility for your research: over $100 \mathrm{M}$ website views per year

At $\mathrm{BMC}$, research is always in progress.

Learn more biomedcentral.com/submissions 